\title{
(IN) CONDICIONES DE LA HOSPITALIDAD: UNA FENOMENOLOGÍA A CONTRAPELO
}

\section{(UN) CONDITIONS OF HOSPITALITY: A PHENOMENOLOGY AGAINST HIM}

\author{
Esteban Marcos Dipaola, Luciano Lutereau* \\ Consejo Nacional de Investigaciones Científicas y Técnicas (CONICET); Universidad de Buenos Aires (UBA), \\ Buenos Aires - Argentina.
}

Recibido marzo de 2018/Received March, 2018

Aceptado agosto de 2018/Accepted August, 2018

\begin{abstract}
RESUMEN
El artículo tiene como objetivo analizar las dimensiones del otro en torno a las figuras de hospitalidad, prójimo, próximo, extraño, intruso, retomando consideraciones desde el psicoanálisis y la fenomenología, así como reformulaciones de la filosofía contemporánea. De este modo, se considera la dimensión histórica de la idea de hospitalidad recurriendo a sus postulaciones en la fenomenología y las revisiones críticas que promueve el psicoanálisis tanto en la figura de Freud como en la de Lacan. La respuesta a la fenomenología acaba de exponerse con las determinaciones de las categorías de "hospitalidad radical" y "responsabilidad", que en la filosofía contemporánea adquieren matices y apropiaciones que posibilitan otras maneras de considerar las figuras de la alteridad y de la subjetividad, y también evaluar problemas y factores de la contemporaneidad evidenciados en las crisis de migraciones y excluidos de la globalización.
\end{abstract}

Palabras Clave: Hospitalidad, responsabilidad, prójimo, subjetividad, extraño.

\begin{abstract}
The article aims to analyze the dimensions of other figures around hospitality, neighbor, near, strange intrusive, taking considerations from psychoanalysis and phenomenology and reformulations of contemporary philosophy. Thus, it is considered the historical dimension of the idea of hospitality using their applications in phenomenology and critical reviews that promotes both psychoanalysis figure of Freud and Lacan. The answer to the phenomenology just exposed to the determinations of the categories of "radical hospitality" and "responsibility" which in contemporary philosophy acquire nuances and appropriations that enable other ways of looking at the figures of otherness and subjectivity, and also assess problems and contemporaneity factors evidenced in crises migration and excluded from globalization.
\end{abstract}

Key Words: Hospitality, responsibility, neighbor, subjectivity, strange.

\section{Introducción}

Lo contemporáneo en su carácter global admite también análisis que otra vez vinculen lo social con una indagación filosófica y que, simultáneamente, se permita impartir tipos de asociaciones con la teoría psicoanalítica. Principalmente si se posee un verdadero interés en interrogar, sobre la mirada de los acontecimientos del mundo actual, condiciones que analicen la hospitalidad y el lugar del otro como un aquel prójimo y semejante, es decir, próximo, pero a la vez extraño, ajeno, distante y hasta enemigo. ¿Qué hacer con el otro? se convirtió en una pregunta vetusta ante la inminencia de esta otra: ¿cómo ser con el otro? Y si pensamos en un otro radical: $¿$ es posible ser con lo ajeno, con lo extraño? ¿Qué tipo de pertenencia

* Autor correspondiente / Correspondig author: estebanmdipaola@ gmail.com 
o reconocimiento puede haber ante la presencia de ese otro radical? ¿Esa pertenencia no será tal vez una impertinencia? Es decir, lo impertinente que viene a acechar como fantasma que puede inquirir, interrogar a mi propio yo.

Dar cuenta de estos problemas obliga a corresponder a ese carácter interdisciplinario que aludíamos entre filosofía, teoría social y psicoanálisis, para recorrer caminos y enlaces de categorías que permitan ser revisitadas en las condiciones centrales de la cultura contemporánea.

Por eso, en este artículo interesa deslindar otras preguntas sobre el prójimo y la alteridad, y desde ahí proponer líneas de intersección con los conceptos de hospitalidad y responsabilidad. El interés primordial es el concepto de hospitalidad, pues consideramos que a partir de éste emergen las formaciones y los hilos teóricos para reflexionar sobre las condiciones del prójimo, del otro, de lo extraño. Más todavía, esta categoría de hospitalidad contiene su mayor valor en su vínculo con aquella otra de responsabilidad. Por esto, la consistencia del artículo remite a una trama conceptual que permita la reflexión constelativa entre las distintas categorías para organizar instancias y líneas de comprensión de transformaciones del lazo social en el capitalismo presente.

\section{El prójimo y el semejante: primeras dimensiones históricas de la hospitalidad}

Desde un punto de vista histórico, el problema del prójimo y el semejante aparece como un descubrimiento y una adquisición de la filosofía moderna; en sentido amplio, podría atribuirse a Hegel el acontecimiento de su promoción más célebre. Hasta entonces, las paradojas agresivas del solipsismo no habían llamado forzosamente la atención de los filósofos, incluido Descartes -para quien el semejante podía ser reconducido a un conjunto de resortes debajo de un sombrero y un abrigo, pero que en el recurso a la garantía divina no vuelve a considerar la cuestión de los otros hombres-.

De este modo, la presencia del otro era considerada como algo de suyo y el único problema que presentaba era de orden estrictamente práctico o moral. Sin embargo, a partir de la Fenomenología del espíritu (1807) ya no estuvo permitido escamotear el problema de la realidad de la alteridad y la posibilidad de un diálogo o un encuentro con dicha instancia que, eventualmente, invirtiese el fundamento de la conciencia.

Asimismo, plantear el problema de la alteridad remite necesariamente a la cuestión de lo extraño, entendido como aquello que no es idéntico a sí. Podría decirse que este punto fue el que Hegel no consideró en su esclarecimiento del conflicto entre (auto) conciencias. Sin embargo, tanto la fenomenología contemporánea como el psicoanálisis se han interrogado por diversas figuras de lo extraño; desde E. Husserl hasta J.-L. Marion (con una inversión de la intencionalidad en su concepción de los "fenómenos saturados"); con S. Freud y J. Lacan (a partir de las distintas modalidades de lo siniestro, lo éxtimo, etc.). En cada caso, una pregunta se formula: ¿cómo introducir una relación con una instancia radical de otredad que no continúe el solipsismo y permita la consideración de la alteridad "en tanto alteridad"? O bien, ¿cómo concebir al sujeto de otro modo que (no sea) en la comprensión empática del redoblamiento especular?

Algunas de estas figuras propias de la reflexión filosófica pueden encontrarse en cuestiones contemporáneas que afectan nuestras concepciones vitales del bien común. En ese sentido, Tortosa encuentra muy atinadamente nociones que organizan normativamente la vida social, utilizando los ejemplos singulares de las reformas constitucionales en Bolivia y en Ecuador:

El Buen Vivir (Sumak kawsay en el quichua ecuatoriano) expresa la idea de una vida no mejor, ni mejor que la de otros, ni en continuo desvivir por mejorarla, sino simplemente buena en los términos definidos por la propia cultura. El Vivir Bien (Suma qamaña en el aymara boliviano) introduce el elemento comunitario, por lo que tal vez se podría traducir como 'buen convivir'.

(Tortosa, 2011, p. 14).

Es claro, entonces, que la relación con la alteridad puede remontarse desde el principio aristotélico de la felicidad como bien común, hasta esas lógicas que norman una vida política en principios constitucionales. Por eso la importancia de definir las nociones que determinan las figuras de lo extraño y lo común para arribar a las indicaciones sobre la hospitalidad que se propone el artículo. 


\section{Lo extraño al yo}

Hace algunos años, P. Ricoeur (1986) propuso considerar la historia de la fenomenología como una sucesión de herejías. Sólo por citar algunas de ellas: -la ontología heideggeriana, que, en la pregunta por el Ser, da un paso más allá del fundamento en la esfera fenomenológica de la conciencia inmanente; -el planteo sartreano de la cuestión del Otro, que suscribe en la estructura de la mirada un motivo para debatir la Quinta de las Meditaciones cartesianas, de E. Husserl, y la vía de acceso al semejante a través de su cuerpo físico; -la filosofía merleau-pontyana del cuerpo, que ubicaría en la percepción el fundamento de la imposibilidad de realización del método de la reducción (del mundo); -por último, en una enumeración incompleta, la subversión que encuentra la noción de intencionalidad en el pensamiento de E. Levinas, al ser subtendida por un estrato de afección y pasividad irreductible.

En cada uno de estos planteos, podría decirse que la fenomenología es subvertida por una dirección hacia lo extraño al Yo. En el curso del siglo XX, la fenomenología exploró un intento de radicalización de sus supuestos, en autores como J.-L. Marion, M. Henry (y quizás no sería injusto añadir aquí a J. Derrida, en sus primeros trabajos), que alcanza para hablar de un "más allá de la esfera del yo trascendental" -entendida esta esfera a partir de la constitución como donación egológica de sentido- que puede tener distintos nombres: Vida, o bien Dios -y este es el modo en que habría que entender lo que D. Janicaud (1991) llamó "el giro teológico de la fenomenología francesa contemporánea"- pueden ser, incluso, nombres de lo extraño.

En cada caso, entonces, la búsqueda de una instancia de alteridad radical es lo que subtiende el contenido de las diversas figuras de lo extraño en la fenomenología contemporánea.

J. P. Sartre fue quien evaluó muy bien la relación entre lo extraño como acontecimiento objetual que se hace presente al sujeto e interviene sobre él. Más aquí en el tiempo, pensadores como J. Derrida y también J. L. Nancy han intervenido en esas dimensiones del análisis filosófico reflexionando sobre el otro, el extraño, el extranjero, en fin, el intruso. Pero antes de atravesar esos pensamientos que nos permitirán concretar el vínculo con la dimensión de la hospitalidad que interesa indagar en el artículo, resulta necesario recorrer algunas tesis provenientes de la fenomenología y del modo en que Lacan recurrió a ella, precisamente, para interrogar lo extraño y la alteridad radical.

\section{El otro radical: una fenomenología a contrapelo}

En la Quinta de las Meditaciones cartesianas Husserl comienza su descripción del acceso a lo extraño a través de una "reducción a la esfera de la propiedad". Se trata, en este caso, de una segunda reducción realizada sobre el precedente de la reducción fenomenológica. Esta reducción implica suspender todos los sentidos que no han tenido su origen en la experiencia del yo, consiguiendo un "ámbito de primordialidad".

El núcleo de la primordialidad lo ocupa el cuerpo propio -punto cero de todas las orientaciones y órgano del movimiento-. El cuerpo propio, a su vez, se revela como sede de un yo psicofísico. En tercer lugar, la esfera primordial abarca los objetos que son accesibles en virtud de los desplazamientos del cuerpo propio así como las obras que dependen únicamente del actuar propio.

El problema de la alteridad radica en que no hay experiencia originaria del otro, dado que "si ocurriera esto, si lo esencialmente propio del otro fuera accesible de modo directo, sería entonces mera parte no-independiente de lo propio de mí mismo, y, en fin, él mismo y yo mismo seríamos uno" (Husserl, 1985, p. 170), esto es, la experiencia de la alteridad sólo puede tener lugar a través de un rodeo mediato en la intencionalidad que apresenta al otro a partir de una aparición perceptiva en el mundo primordial propio: el cuerpo físico extraño. Este proceso tiene tres instancias.

En un primer momento, el cuerpo físico extraño recibe el predicado de cuerpo propio mediante una transferencia analogizante de sentido a partir del único cuerpo propio que puede darse originariamente en la esfera de la primordialidad: el propio. Se trata de una apercepción asemejadora a la que Husserl da el nombre de "parificación". Se transfiere al cuerpo físico ajeno el sentido cuerpo propio. La apresentación que se dirige al cuerpo propio extraño se extiende, a la vez, al yo psicofísico extraño como yo que lo gobierna y es centro de aparición de un mundo.

En un segundo momento, la apresentación de lo extraño recibe cierta verificación mediante la confirmación de las anticipaciones vacías del comportamiento del cuerpo extraño. En la 
parificación se transfiere al cuerpo físico extraño no sólo el comportamiento actual sino todo el sistema de comportamiento. Por lo tanto, es posible hacer anticipaciones del comportamiento extraño a partir del comportamiento propio esperable en circunstancias similares.

En un tercer momento, se produce la presentificacion de las apresentaciones de lo extraño mediante el recurso a la empatía. La empatía presentifica las perspectivas ajenas como si el cuerpo propio ocupara el lugar del otro. De este modo, puede concluirse, el semejante es para Husserl una modificación intencional del sí mismo. Este aspecto es el que tradicionalmente ha sido criticado en diversos autores de la tradición fenomenológica, como una reducción de la alteridad a una instancia de mismidad.

B. Waldenfels, en un artículo titulado $L a$ experiencia de lo extraño en la fenomenología de Husserl (1989) afirma esta conclusión del modo siguiente: "El remedio metódico universal que Husserl proporciona consiste en quitar a lo extraño el aguijón de la pura exterioridad con transformaciones del sí mismo y de lo mismo" (Waldenfels, 1989, p. 18).

No obstante, Waldenfels también subraya que en los conjuros de lo extraño se encuentra una indicación implícita de su presencia; y que, por lo tanto, podría sostenerse -lo mismo que en la Crisis se dijera de Galileo- que Husserl fue un encubridor, pero también un descubridor. Asimismo, lo extraño, para Husserl, no sólo radica en la presencia del semejante, sino que es extensible, por ejemplo, al mundo de los animales y a lo lejano, ya que por mediación de la "empatía indirecta" se puede ampliar el horizonte de experiencias más allá del pasado efectivamente vivido, en una extensión retrospectiva, pero también acceder a una comunicación entre generaciones o a una interpretación de las "huellas de animales", y proponer un mundo pre-humano, en la naturaleza, etc. En cierto aspecto, esto lo pone en evidencia también el análisis de la perspectiva husserliana respecto a la vinculación entre la persona y los objetos, tal como lo señala Enrique Muñoz en un artículo que analiza esa problemática:

La persona o el ser humano -casi escribiría uno el "Dasein"- está en el mundo, lo habita y está en relación con él, con las cosas. De hecho, uno se vincula directamente con los objetos que se encuentran en el entorno más inmediato; por ejemplo, yo toco la silla en que me siento, la mesa en que trabajo o la cerradura de la puerta que abro. Hay una relación psicofísica con estas cosas. Pero, además, uno es atraído por objetos que no están en mi cercanía, pero que de igual forma afectan mis sentidos; por ejemplo, la belleza de una montaña nevada, la claridad del cielo o el canto de un ave. En definitiva, la tesis de Husserl es que la persona o el ser humano está condicionado, no psíquicamente, pero sí por las cosas. (Muñoz, 2012, p. 100).

El yo vive acosado por huellas de lo extraño. Por eso, "lo extraño en su forma radical es lo extraño al yo" (Waldenfels, 1989, p. 9). Esta idea puede ser evaluada también desde las perspectivas que revelan en la empatía una instancia de "prosocialidad", tal como entienden Noguera, Martí-Vilar y Almerich:

Las relaciones de la empatía aparecen como el principal motivador de la prosocialidad, en sus componentes cognitivos y emocionales para quienes la empatía juega un rol clave en el desarrollo de la comprensión social favoreciendo la prosocialidad y sirviendo de fundamento para las relaciones personales. (Noguera, Martí-Vilar \& Almerich, 2014, p. 162).

Es Lacan quien en el Seminario La angustia formula una de las críticas más severas a la tradición fenomenológica.

Luego de más de 20 años (entre 1932 y 1953), en los que Lacan permaneció orientado según ciertos motivos básicos de la fenomenología, a partir del seminario Los escritos técnicos de Freud (1953-54) desarrolló un cuestionamiento progresivo de distintos motivos fenomenológicos -el método jaspersiano de las relaciones de comprensión, la concepción heideggeriana del lenguaje, etc.- cuyo punto álgido de debate inicia en el seminario Las psicosis (1955-56), con la crítica a la psicogénesis (que había sido defendida en 1946, en un debate con H. Ey, en la ponencia "Acerca de la causalidad psíquica") y la máxima de "no comprender".

En este contexto, el semejante condesciende a su presentación como figura de lo extraño, en sentido radical, y sólo reviste su presencia como soporte de la intervención del analista sobre el texto del decir de la cadena significante. 
Sin embargo, a partir del seminario $L a$ angustia, la enseñanza de Lacan despliega una relectura de lo imaginario, que ya no puede ser equiparado a lo especular. En el trayecto que discurre entre el seminario La transferencia y la introducción del objeto $a$ en este seminario, Lacan realiza una reinterpretación de los esquemas ópticos, cuyo fundamento ya no se encuentra solamente en aquello que se refleja en la asunción jubilosa de la imagen corporal -como modelo de la relación con el otro especular, reducido a un desdoblamiento yoico-, sino en la presencia latente de un objeto que no es "especularizable".

Retomando el artículo de Waldenfels mencionado anteriormente, es interesante notar que el autor -en una nota al pie-formula una indicación lateral a Lacan, aunque meramente anecdótica y sin desarrollo. Para Waldenfels, la concepción lacaniana de lo especular-convergente con los desarrollos del último Merleau-Ponty, en Lo visible y lo invisible (1964) - puede ser una vía regia de acceso a una figura de lo extraño que no pueda ser subsumida en la mismidad. En lo que resta de esta introducción intentaremos explicitar el sentido implícito de esa mención.

En el seminario La angustia, Lacan toma el fenómeno clínico de la angustia como hilo conductor para introducir la categoría de objeto a. Además de la angustia, otros fenómenos clínicos son estudiados, en una minuciosa descripción de sus coordenadas de aparición: el duelo, el actingout, la experiencia de lo siniestro, etc. En cada uno de estos casos, el propósito de Lacan es presentar y esclarecer ciertos fenómenos que no pueden ser reconducidos a la correlación sujeto-objeto. La correlación intencional desfallece frente a la situación de angustia $-y$, en este punto, Lacan recuerda la "nada" heideggeriana-, pero también flaquea en el duelo, en cuyo centro Lacan invierte la fórmula freudiana de la melancolía para sostener que aquello que se pierde no es el correlato de una nóesis. En términos generales, todo el seminario se expone como una fenomenología del extrañamiento, a través de la localización de ciertos motivos clínicos que implican un margen relativo de extrañeza para quien los padece -así es como, por ejemplo, en el acting-out, lo definitorio no es que se trate de una conducta, más o menos compulsiva o extravagante, sino que quien la realiza la vive como "inmotivada"; de ahí que Lacan designe el acting-out como "verdad sin sujeto"-.
Es en este punto que puede esclarecerse el sentido de la frase citada en un comienzo: el extravío de Husserl consistiría en haber reducido el fenómeno a una forma de objetividad. Como fuera dicho, no es este el lugar para evaluar todo el alcance de la crítica de Lacan a la fenomenología; no obstante, es preciso destacar que la misma crítica había sido realizada por Levinas en su tesis de 1930 acerca de la intuición en la fenomenología husserliana (y toda la tradición fenomenológica francesa continuó por el mismo derrotero). Por lo tanto, es preciso subrayarlo una vez más, sería erróneo considerar que se trata de una crítica a la fenomenología, la propuesta por Lacan, sino de un tipo aproximación a los fenómenos.

Del mismo modo, la concepción de un más allá de la representación intencional, en la consideración del objeto $a$, puede notarse en la descripción de lo siniestro. El extrañamiento en cuestión tiene su eje capital en el fenómeno del doble, que Lacan propone no concebir simplemente en base a la teoría del animismo; o bien, no tomar esa perspectiva a menos que se la pueda subsumir en una perspectiva más amplia, la del objeto $a$.

El fenómeno del doble evidencia, según Lacan, una alteración en la aparición del semejante, que ya no se presenta como un mero desdoblamiento especular, sino como correlato incomprensible de algo íntimo y extraño al yo. Podría decirse que la especificidad del psicoanálisis radica en atisbar que eso extraño al yo es lo más propio de su constitución subjetiva. De este modo, el psicoanálisis podría proponerse una extensión del programa fenomenológico, aunque apreciando que los fines que lo subtienden son otros. Así, por ejemplo, en el artículo de Waldenfels que se viene comentando, el autor destaca que la perspectiva de Husserl siempre fue la de evidenciar la constitución de la alteridad, antes que poner de manifiesto aquellos fenómenos que la cuestionan. Dicho de otro modo, la egología husserliana estaba predestinada a sostener el carácter intersubjetivo de la donación de sentido; mientras que el psicoanálisis, eventualmente, recorre el camino inverso: partiendo de los fracasos de la intencionalidad, se reconduce a aquellos fundamentos irreductibles de lo extraño.

En conclusión, a pesar de sus divergencias, ambas disciplinas convergen en el interés por explorar el trasfondo extraño al yo de la subjetividad, en un recorrido expositivo que se apoya 
en la consideración del semejante y la alteridad como posibles formas de lo extraño.

Es aquí, creemos, donde puede establecerse un puente de reflexión y análisis para pensar la condición de la hospitalidad como apropiación del yo en esa presencia absoluta de un otro radical

\section{El prójimo objeto como un próximo sujeto}

Si la figura de lo extraño aparece, ella remite a su vez a la extrañeza y, también, a esa extrañeza constitutiva de una alteridad. Carlos Thiebaut lo explica correctamente en un recorrido acerca de una dimensión particular como la de "auto-extrañeza" con la que señala aspectos propios de la idea de "tolerancia", y expone:

Esa auto-extrañeza está en la base de la tolerancia, es el movimiento que da lugar a que nazca, y, a la vez, es su efecto más inmediato. Que el otro exista y que reconozcamos al otro introduce un pliegue de otreidad en nosotros mismos. Ante el otro que llegamos a aceptar, a reconocer, nosotros mismos nos hacemos, en parte, unos otros de nosotros mismos. (Thiebaut, 2010, p. 543).

Por eso el autor continúa con la idea de que el reconocimiento se advierte cuando se observa su afectación al no poder tolerar aquello que hiere el propio reconocer nuestra identidad, o nuestras mismas formas de tolerancia y de hospitalidad (Thiebaut, 2010).

Por eso, es importante mostrar las formas en que el reconocimiento del otro determina, además, condiciones de responsabilidad. Aspectos de la singularidad de lo extraño fueron abordados por Sartre, y si fuera necesario traducir en una frase o pregunta eso que para el filósofo francés podría ser definido como la "estructura ontológica de la conciencia", es decir, la ontología de un ser-paramí, podríamos presentar la siguiente interrogación: ¿cómo soy yo? Resolviendo la imposible dialéctica de una pregunta semejante, deberíamos responder que soy como soy visto en un reconocimiento. El primer planteo sartreano para establecer esto es la consideración de la vergüenza. Tener vergüenza es de algo, pero sobre todo ante alguien, de allí que Sartre sostenga:

el prójimo es el mediador indispensable entre mí y mí mismo: tengo vergüenza de mí tal como me aparezca al prójimo. Y, por la aparición misma de un prójimo, estoy en condiciones de formular un juicio sobre mí mismo como sobre un objeto, pues al prójimo me aparezco como objeto. (Sartre, 2004, p. 250).

De este modo, en esa mediación que hace volver objeto sobre una condición de subjetividad, se atestigua que la vergüenza es forma de reconocimiento: "Reconozco que soy como el prójimo me ve" (Sartre, 2004 , p. 250). Pero si nos quedáramos simplemente en este punto el avance no sería más significativo que lo conocido a través de Hegel en su Fenomenología del espíritu y que suele sintetizarse en la noción de autoconciencia, sin embargo, Sartre añade la condición de la responsabilidad: "Pero este nuevo ser que aparece para otro no reside en el otro: yo soy responsable de él" (Sartre, 2004 , p. 250). Esto significa que me reconozco como ser en tanto soy una aparición para otro, pero, al tiempo, soy responsable del ser de esa aparición. En esta idea de prójimo que explica Sartre encontramos la semilla del carácter de "hospitalidad radical" que promueve Derrida. Para Derrida la hospitalidad no es nunca por fuera de la responsabilidad; o, en línea con el argumento sartreano, podemos decir que hospitalidad es mi reconocimiento en el otro como responsabilidad. En una posición semejante Martínezez Farrero sigue las indicaciones de Levinas para dirimir la concurrencia de lo Mismo y lo Otro, cuando analiza:

El sujeto está en el límite del mundo y es
gracias al lenguaje y el diálogo consigo
mismo y los demás, que consigue vincu-
larse al mundo. Por consiguiente, podemos
afirmar que el sujeto surge, existe, en tanto
que habla, ya sea con los demás o consigo
mismo. (Martínezez Farrero, 2017).

En esa concepción el análisis del autor ordena la instancia del reconocimiento de sujeto en la facultad de hablar, continuando una pronunciada tradición que liga subjetividad a lenguaje.

Ahora bien, la relación entre responsabilidad y subjetividad evidencia más claramente si proseguimos con el análisis de Sartre en El ser y la nada, en lo relativo a la condición de la mirada. El prójimo aparece a nuestra mirada primeramente, en cuanto relación fundamental conjetural, como objeto, es decir, el otro se me representa como 
una objetividad y esa es mi percepción primera, pero no es la constitutiva del otro como alguien prójimo, es decir, próximo. El próximo a mí es aquel que me vuelve a mi relación fundamental ya no de manera conjetural sino probable, esto es, como ser-para-otro; y por esto es en la mirada que el prójimo es ahora sujeto. Así, si el prójimo no es simplemente aquel que veo, sino aquel que me ve, lo que aparece con ello es la figura del Cogito, pero ahora como sujeto-otro. La objetividad primera deja de ser la percepción representada cuando reconozco en el otro una mirada que me define a mí como próximo. En términos de Sartre, lo que hace el prójimo cuando se revela en su proximidad es destotalizar el universo sobre el que se sostenía mi posición de sujeto y que hacía del prójimo una visión de objeto. Pero el ser-visto por otro me constituye en objeto de una tal visión $y$, por efecto, constituye al otro en sujeto; de ese modo, la proximidad es lo ajeno, a la vez que el ser-visto como prójimo constituye la realidad de una relación entre sujetos. Dice Sartre:

si el prójimo-objeto se define en conexión con el mundo como el objeto que ve lo que yo veo, mi conexión fundamental con el prójimo-sujeto ha de poder reducirse a mi posibilidad permanente de ser visto por el prójimo. En la revelación y por la revelación de mi ser-objeto para otro debo poder captar la presencia de su ser-sujeto. (Sartre, 2004, p. 284).

En ese encuentro fundamental concebía Sartre la posición de sujeto. No estamos solos sino que es en la compañía, en el ser-con que comprendemos el mundo como sujetos, y ello, al tiempo, se sustenta en la mirada, porque "si el prójimo es, por principio, aquel que me mira, debemos poder explicitar el sentido de la mirada ajena" (Sartre, 2004, p. 285).

Entonces, alcanzamos la noción de que el otro es alguien próximo a la vez que es lo ajeno. En ese punto es que el requerimiento de responsabilidad para pensar la hospitalidad adquiere un sentido fuerte. La hospitalidad se condice con la presencia irremediable del otro; alteridad que solo existe en su extrañeza, es decir, es el extranjero que viene a situarse sobre el lugar que se me presenta como propio ejerciendo una despropiación. Entonces, es el ajeno y es un intruso porque impone la diferencia sobre lo que era propio, así lo propio es también ajeno, lo que me pertenecía es una intrusión. Por eso la hospitalidad es también hostil, y en tal sentido la responsabilidad es la posición ética que la sustenta.

\section{Hospitalidad y responsabilidad: una ética de la intrusión}

Según Derrida, la hospitalidad es una poética por cuanto se vincula con la invitación, pero a la vez con la invención. Por esto, la hospitalidad afronta como punto de partida la pregunta. Una pregunta que es del extranjero y venida del extranjero y, por tanto, el extranjero se convierte así en lo que amenaza el principio determinante de nuestro lugar institucional, amenaza nuestra lengua, pone en entredicho al "dueño de casa". Así, la cuestión del extranjero es la cuestión primera de la hospitalidad, en tanto remite a ésta a la cuestión primera del ser.

El problema central de la reflexión de Derrida será, entonces, el "derecho de hospitalidad" y las condiciones que ese derecho incluye. De allí que el problema de la lengua se corrobore como relevante, pues una consideración es si corresponde exigir al extranjero que hable nuestra lengua, si es exigible que abandone su lugar propio, su lengua materna para someterse a la lengua del otro ${ }^{1}$. De esa manera, la hospitalidad se convierte en un pacto, en un contrato que obliga al otro y enmienda la recepción. Se ofrece al extranjero un derecho de hospitalidad, que es, inmediatamente, un derecho de ciudadanía. Entonces, la hospitalidad se constituye sobre el linde de la paradoja y la contradicción, pues la relación de hospitalidad se agota también en su consumación y su pacto. Al respecto dice Derrida:

una paradoja o una contradicción: ese derecho a la hospitalidad ofrecido a un extranjero "en familia", representado y protegido por su apellido, es a la vez lo que hace posible la hospitalidad o la relación de hospitalidad con el extranjero y al mismo tiempo el límite y la prohibición. (Derrida \& Dufourmantelle, 2000, p. 29).

Entonces, cabe pensar en las condiciones de una hospitalidad absoluta. En el caso ya no simplemente del extranjero, sino de un otro absoluto, un extraño, un intruso si se quiere, "supone una ruptura con la hospitalidad en el sentido habitual, 
con la hospitalidad condicional, con el derecho o el pacto de hospitalidad" (Derrida \& Dufourmantelle, 2000 , p. 31). Se trata de dar lugar al otro absoluto, al desconocido y anónimo. Esto es, a ese intruso que carece de nombre y de pertenencia, lo dejo venir, lo hago llegar, hago que tenga lugar allí donde lo ofrezco, sin exigir reciprocidad (lo que implicaría la formulación de un pacto). De este modo, como nos sugiere Derrida, "la ley de la hospitalidad absoluta ordena romper con la hospitalidad de derecho" (Derrida \& Dufourmantelle, 2000, p. 31); porque se trata de una "hospitalidad justa" que dispone lo que Lévinas (2003) entiende como la esencia de una responsabilidad. En esa responsabilidad originaria, la hospitalidad ya no puede producirse en la interrogación del otro, en la garantía de su identidad, su nombramiento, al contrario, esa modalidad de responsabilidad obliga ante el otro en su radical ser: la acogida del otro es sin pregunta y sin nombre. Se ofrece la hospitalidad antes de cualquier identificación y de cualquier derecho, porque se responde a una responsabilidad originaria.

Por esto mismo, Derrida remite a las derivaciones latinas de extranjero: el extranjero puede ser hostis, el que es recibido como huésped; o también puede ser hôte, el enemigo. Por eso hospitalidad y hostilidad se vinculan en su raíz, y de ello puede remitirse a una hostipitalidad. Porque en definitiva se procura establecer los límites de la hospitalidad y, principalmente, aquellos que la remiten a una condición de derecho de ciudadanía, en donde la hospitalidad se cierra y anula, o esa forma de hospitalidad que recibe al otro absoluto, en su extraña radicalidad:

Hoy una reflexión sobre la hospitalidad supone entre otras cosas, la posibilidad de una delimitación rigurosa de los umbrales o de las fronteras: entre lo familiar y lo no familiar, entre lo extranjero y lo no extranjero, el ciudadano y el no-ciudadano, pero sobre todo entre lo privado y lo público, el derecho privado y el derecho público, etc. (Derrida \& Dufourmantelle, 2000, p. 51).

El problema es que la hospitalidad juega también un valor de soberanía y, asimismo, de reconocimiento. El derecho de hospitalidad es también el reconocimiento de mi hospitalidad o de mi soberanía sobre el hogar propio, y en ese sentido es un derecho de exclusión. La inscripción de la hospitalidad en un derecho es un acto de reconocimiento del poder de soberanía y, por lo tanto, una condición a la que es inherente la desigualdad. Por eso la hospitalidad debe corresponderse con la singularidad de una "ley sin imperativo, sin orden sin deber. Una ley sin ley" (Derrida \& Dufourmantelle, 2000, pp. 85 y 87).

Entonces, en la hospitalidad absoluta, el otro me ocupa, no solo pasa el umbral de mi hogar, sino que toma mi lugar, se apodera de lo que soy, pero para ser lo que no deja de venir, porque está ya adentro formando parte. "Es como si el extranjero poseyera las llaves", dice Derrida, indicando no un poder nuevo sobre el hogar, sino una metamorfosis de la relación, una forma distinta de reconocimiento donde no asisto al otro, sino que me hago con el otro.

En una línea similar, Jean-Luc Nancy (2007) en El intruso afirma que todo extranjero para conservar algo de su ajenidad debe participar en la relación como un intruso. Si contara con derecho de entrada y residencia, ya no podría definirse como extranjero. De esta forma, el extranjero está siempre llegando, nunca cesa su llegada. Es una perturbación de la intimidad, porque nunca deja de ser un intruso. Por eso para Nancy, se vive con lo ajeno a punto de convertirse uno mismo en esa ajenidad ${ }^{2}$. El intruso expone a uno, lo excede, viene a indicar la verdad del sujeto. Así, Nancy concluye:

\begin{abstract}
El intruso no es otro que yo mismo y el hombre mismo. No otro que el mismo que no termina de alterarse, a la vez aguzado y agotado, desnudado y sobreequipado, intruso en el mundo tanto como en sí mismo, inquietante oleada de lo ajeno, conatus de una infinidad excreciente. (Nancy, 2007, p. 45).
\end{abstract}

Entonces, la incondicionalidad de recibir al otro es convertirse en ajeno junto a éste, en afectarse en indefinidas sustituciones. Por eso, del mismo modo que Lévinas observa la responsabilidad como otra forma de ser con el otro, la hospitalidad absoluta es ley contra la ley, ley contra el derecho, un juego de sustituciones donde cada uno es anfitrión y rehén a la vez del otro. Es la invención permanente del otro.

Es necesario apreciar que en Emmanuel Lévinas (2003) la ética es pre-ontológica y prefigura la esencia del ser y de los entes. Entonces, el 
deber moral tiene como horizonte esa realidad otra, dicha antes de ser expresada, en la que se sustenta la precedencia de lo ético sobre lo ontológico. Por eso, toda responsabilidad en Lévinas es ante algo o alguien. Para Lévinas siempre existe el otro como exterioridad radical y ante él somos responsables. De tal manera, el axioma que es punto de partida para Lévinas indica: "pasar a lo otro que el ser, de otro modo que ser" (Lévinas, 2003, p. 45). Ahí mismo se funda toda responsabilidad y toda ética.

Entonces, la ética es constitutiva del otro. Mi otro modo que ser es el conatus por el cual persiste mi esencia, pero en tanto responsabilidad con un otro que me habita y por quien puedo ser: la responsabilidad con el prójimo. La diferencia es trascendental porque me viene en la esencia de mi ser en otro. No soy el otro, pero soy responsable por él por el simple hecho de estar comprendido como ser, como subjetividad en la humanidad. Por esto, la responsabilidad para con el otro es pre-ontológica y pre-original; es "el no-lugar de la subjetividad" (Lévinas, 2003, p. 54). No es mi compromiso, mi decisión ni mi libertad y la comprensión de la libertad del otro, lo que me hace responsable. Mi responsabilidad con el otro es anterior, incluso a mi relación como ser y como sujeto.

Cuando Lévinas afirma: "La subjetividad en su ser deshace la esencia sustituyéndose por el otro. En tanto que uno-para-el-otro se absorbe en significación, en decir o verbo del infinito. La significación precede a la esencia" (Lévinas, 2003 , p. 58). Esto revela que el sujeto lleva en sí la imposibilidad de descargarse la responsabilidad. La alteridad pura es una proximidad, y se trata de una proximidad como contacto, como sinceridad de la exposición:

La subjetividad es el Otro-en-el-Mismo, según un modo que también difiere de la presencia de los interlocutores, uno al lado del otro en un diálogo en el que están en paz y de acuerdo uno con el otro. El Otro en el Mismo de la subjetividad es la inquietud del Mismo inquietado por el Otro. (Lévinas, 2003, p. 72).

Estar con el otro es, de esta manera, un ser con el otro o, más todavía, en el Otro. El otro me conmueve en su estar, por tanto, debo recibirlo y anudarlo en mi subjetividad. El ser significa en la proximidad del otro, es decir, en su hospitalidad con lo extraño.

\section{Conclusiones}

El recorrido propuesto posibilitó delinear algunas dimensiones de la categoría de hospitalidad tanto en su trayectoria histórico-conceptual desde la modernidad como en su expresión reflexiva para las condiciones del mundo contemporáneo. En este último aspecto, es central un retorno a las indagaciones sobre la otredad que permitan reflexiones críticas sobre acontecimientos y experiencias concretas de nuestra situación contemporánea y sus redes globales. Las denominadas "sociedades del riesgo" ( $c f$. Beck, Giddens) ordenan reflexivamente nuestras acciones de acuerdo a lo inmediato y la incertidumbre y sobre ese plano es necesario revitalizar concepciones cuyo efecto estimule una interpretación de la vida presente; como indica Galindo: "lo que el teorema de la sociedad del riesgo afirma es que en la modernidad dichas decisiones potencialmente perniciosas adquieren rasgos inéditos" (Galindo, 2015, p. 158). De esta manera, el situarnos sobre los riesgos no determina una reordenación ontológica de lo social, para el pensador, sino algo establecido:

por la emergencia de una semántica que permite caracterizar a la nuestra como una época riesgosa. Y, si bien, el paso de la modernidad simple a la modernidad reflexiva no se verifica exclusivamente por la emergencia de dicha semántica, queda de manifiesto que ésta ha desempeñado un rol fundamental en el proceso de transición. (Galindo, 2015, p. 158).

Esos riesgos también se clarifican cuando se observan y analizan los fenómenos migratorios con sus novedades, las condiciones de lo que en el último tiempo sectores políticos y mediáticos han llamado la "crisis de los refugiados", como así también el modo en que las estructuras económicas de los países centrales empiezan a colisionar con las de los países emergentes, vuelven inescindible retomar el tipo de problemas, interrogaciones y análisis que en este artículo promovemos como instancia de apertura y comienzo. En este último aspecto mencionado, cabe indicar las alteraciones de relaciones de autoridad que se promueven y que potencian el pensamiento de la hospitalidad. Así Ortega-Senet indica modos de reflexión acerca de 
la organización de la autoridad que efectúen reglas de variación entre sistemas: "cada sistema puede darse reproducción de hegemonía y, simultáneamente, tener otras dinámicas distintas, lo cual va a depender de los contextos y momentos de cada sistema" (Ortega-Senet, 2017, p. 431). En ese enfoque la perspectiva de la hospitalidad puede influir para interrogar otros modos de disposición de la relación con un otro.

Entonces, problematizar la idea de hospitalidad legada por J. Derrida en conexión con una noción de responsabilidad originaria promovida por E. Levinas, pero a su vez retornando a principios de la fenomenología y a reformulaciones del psicoanálisis en la obra de J. Lacan concreta articulaciones y constelaciones conceptuales que deben servir a la búsqueda permanente de una filosofía que no se desentienda de los dilemas concretos de la contemporaneidad sobre la cual está obligada a pensar(se).

El extraño en su radicalidad es aquel que modifica el lugar de la interrogación y que, mediante ello, obliga a remitir el pensamiento a su otro, es decir, en acuerdo con Nietzsche: un pensamiento que se someta a las fuerzas de la vida. La hospitalidad absoluta, entonces, es también una manera de suscribir un pensamiento crítico sobre la propia condición de la reflexión filosófica y también de esas intersecciones entre el psicoanálisis y la teoría social. 


\section{Referencias}

Derrida, J. \& Dufourmantelle, A. (2000). La hospitalidad. Buenos Aires: Ediciones de la Flor.

Galindo, J. (2015). El concepto de riesgo en las teorías de Ulrich Beck y Niklas Luhmann. Acta sociológica, 67, 141-164.

Husserl, E. (1985). Meditaciones cartesianas. México: Fondo de Cultura Económica.

Janicaud, D. (1991). Le tournant théologique de la phénoménologie française. Paris: Éditions de L'Éclat.

Lacan, J. (2007). El seminario 10: La angustia. Buenos Aires, Paidós.

Levinas, E. (2003). De otro modo que ser o más allá de la esencia. Salamanca: Sígueme.

Martínezez Farrero, P. (2017). La importancia del nombre propio en la constitución del sujeto. Revista de Humanidades [en línea], 30. Recuperado de: http://www.revistadehumanidades. com/articulos/137-la-importancia-del-nombre-propio-en-laconstitucion-del-sujeto.

Muñoz, E. (2012). Fuentes fenomenológicas de la noción de persona: su discusión en Husserl, Scheler y Heidegger. Areté. Revista de Filosofía. XXIV(1), 91-108.
Nancy, J-L. (2007). El intruso. Buenos Aires: Amorrortu.

Noguera, J. J., Martí-Vilar, M., \& Almerich, G. (2014). Responsabilidad social universitaria: influencia de valores y empatía en la autoatribución de comportamientos socialmente responsables. Revista Latinoamericana de Psicología, 46(3), 160-168

Ortega-Senet, M. (2017). Relaciones de poder y proceso de cambio. Formas de autoridad en la praxis y los imaginarios de jóvenes participantes del Taller de Formación Política en El Alto, Bolivia. OBETS. Revista de Ciencias Sociales, 12(2), 425-450. Ricoeur, P. (1986). Á l'école de la phénoménologie. Paris: Vrin. Sartre, J-P. (2004). El ser y la nada. Buenos Aires: Biblioteca Grandes Pensadores.

Thiebaut, C. (2010). Tolerancia y hospitalidad: una reflexión moral ante la inmigración. ARBOR. Ciencia, pensamiento y cultura, 744, 543-554.

Tortosa, J. M. (2011). Vivir bien, buen vivir: caminar con los dos pies. OBETS. Revista de Ciencias sociales, 6(1), 13-17.

Waldenfelds. B. (1992). La experiencia de lo extraño en la Fenomenología de Husserl. Escritos de Filosofía, 21-22, 3-20. 


\section{Notas}

1 Añade Derrida: "los extranjeros absolutos, siguen a menudo reconociendo la lengua, la lengua llamada materna, como su última patria, incluso su última morada" (Derrida \& Dufourmantelle, 2000, p. 91).
2 Recordemos que Jean-Luc Nancy escribe y dicta la conferencia sobre El intruso haciendo referencia a un trasplante de corazón que le hubiera sido hecho unos años antes. 